\title{
A QUESTÃO MIGRATÓRIA E AS ESTRATÉGIAS DE CONVIVÊNCIA ENTRE CULTURAS DIFERENTES EM PORTUGAL
}

\author{
Bárbara Bäckström* \\ Sofia Castro-Pereira*
}

\begin{abstract}
Este artigo dá conta de uma reflexão teórica sobre a convivência entre culturas diferentes em Portugal. A partir de uma breve caracterização da imigração em Portugal, num primeiro momento procurou-se definir e distinguir os diferentes modelos teóricos de integração para, num segundo momento, analisar concretamente as políticas públicas relativas à integração dos imigrantes na sociedade portuguesa. Por último, partindo da constatação de que os estudos dão conta de comparações entre culturas e não tanto da convivência entre elas, procurou-se refletir sobre as razões subjacentes à quase total ausência de investigações cujo enfoque seja a convivência entre culturas.
\end{abstract}

Palavras-chave: Imigração em Portugal; Políticas Públicas de Integração; Interculturalidade; Multiculturalismo.

Todos os anos, milhões de pessoas atravessam fronteiras internacionais para irem viver num outro país. ${ }^{1}$ A deslocação implica, quase sempre, sacrifícios e incertezas, uma vez que a adaptação a um

\footnotetext{
* Licenciada em sociologia pela Faculdade de Ciências Sociais e Humanas, Universidade Nova de Lisboa, Mestre em Demografia histórica e social pela Universidade Aberta pela Faculdade de Ciências Sociais e Humanas, Universidade Nova de Lisboa, Doutora em Saúde internacional pelo Instituto de Higiene e Medicina Tropical da Universidade Nova de Lisboa. É professora auxiliar na Universidade Aberta e investigadora no CEMRI/ Universidade Aberta. Lisboa/Portugal.

** Licenciada em Antropologia pela Faculdade de Ciências Sociais e Humanas, Universidade Nova de Lisboa, Mestre em Relações Interculturais pela Universidade Aberta. Bolseira da Fundação para a Ciência e Tecnologia, frequenta o Programa de Doutoramento em Sociologia no ISCTE-IUL. É investigadora no CEMRI/Universidade Aberta. Carnaxide/Portugal.

1 PNUD. Relatório de Desenvolvimento Humano 2009 - Ultrapassar Barreiras: Mobilidade e Desenvolvimento Humanos.
} 
novo país, com códigos culturais e visões do mundo frequentemente diferentes, é um desafio que se coloca quer aos migrantes quer aos cidadãos do país a que se dirigem com o intuito de melhorarem os seus padrões de vida.

Compreender a questão migratória implica necessariamente que se objetive o que se entende por multicultural e intercultural, considerando a interculturalidade como um desafio capaz de reconhecer e valorizar a diferença. Pois não basta somente que as diferentes culturas consigam uma convivência no respeito mútuo e na solidariedade, apesar de isso por si só ser positivo, mas uma interação significativa das culturas em presença. Se olharmos para a Europa, rapidamente nos apercebemos do surgimento de diferentes iniciativas no combate ao racismo e xenofobia, apontando a Europa como um palco de problemas complexos de convivência entre diversas culturas.

Olhando para Portugal, observamos que até finais da década de 1960, este é, indiscutivelmente, um país de emigração. Mas, após a descolonização, que se seguiu à Revolução de Abril de 1974, a situação inverte-se passando a ser também um país de imigração. Até a década de 1990, Portugal foi sobretudo procurado por habitantes dos países lusófonos, mas atualmente preponderam os oriundos do Brasil e dos países do leste da Europa. Também a partir dos anos 90, por via terrestre, chegam imigrantes originários da China.

Portugal é assim, desde os anos 80, país de destino e de origem de migrações internacionais. Finda a fase da imigração para Portugal, associada ao processo de descolonização dos antigos territórios africanos, a imigração portuguesa iniciou uma nova etapa, nos anos oitenta, caracterizada pela procura crescente de trabalhadores em setores intensivos em mão-de-obra, com baixos salários e elevado grau de informalização, nomeadamente, para a construção civil no caso dos homens e serviços de limpeza, industriais e domésticos no caso das mulheres. À medida que a imigração foi aumentando, assistiu-se ao alargamento e diversificação das áreas de recrutamento. À semelhança do que aconteceu noutros países da Europa do Sul, no último quarto de século, registou-se um assinalável aumento da imigração dos Países Africanos de Língua Portuguesa e do Brasil e, mais recentemente, dos países da Europa de Leste e da ex-URSS. 
Nos finais dos anos 90 do século XX, a imigração em Portugal alterou-se quer em quantidade, quer em termos de origens. Portugal tem hoje cerca de meio milhão de imigrantes ${ }^{2}$ que representam cerca de $10 \%$ da população ativa e cerca de $5 \%$ da população residente. Os imigrantes são oriundos de mais de 150 países dos quatro cantos do mundo e falantes de cerca de 230 línguas maternas e dialetos diferentes. ${ }^{3}$

A partir de 2000, assistiu-se a uma viragem do panorama da imigração em Portugal observando-se mudanças a três níveis ${ }^{4}$ : Diversificação da origem dos fluxos e alteração do peso relativo dos imigrantes; diferenciação no seu perfil e definição de novos padrões de dispersão territorial. Miranda ${ }^{5}$ acrescenta ainda um quarto nível com o aumento significativo da imigração feminina a solo. Segundo Trovão e Ramalho ${ }^{6}$, a feminização pode-se contabilizar em termos de taxas de crescimento por gênero entre 1999 e 2007. Por exemplo, no caso da Guiné-Bissau a taxa de crescimento deste fluxo migratório rumo a Portugal entre estes dois períodos foi $51 \%$ para os homens e $111 \%$ para as mulheres. Segundo o Relatório estatístico do SEF para 2010, verifica-se o predomínio de títulos emitidos a cidadãos do sexo feminino, designadamente nos casos do Brasil, Cabo Verde, Ucrânia, China, Moldávia e Angola.

É na região de Lisboa que a grande maioria dos imigrantes vivem e trabalham. Lisboa transformou-se numa metrópole multicultural como outras grandes cidades europeias. ${ }^{7}$ Por esta razão também é nesta cidade que se verificam alguns dos principais problemas de integração, de etnização da pobreza e da exclusão. ${ }^{8}$ Até agora diversos estudos analisam

2454.191 cidadãos não-nacionais em Portugal em 2009 (SEF - Serviço de Estrangeiros e Fronteiras. Relatório estatístico anual 2009), verificando-se um decréscimo da população residente nãonacional em 2010, 445.262 cidadãos estrangeiros, o que corresponde em termos percentuais a menos $1.97 \%$ face ao ano precedente (SEF - Serviço de Estrangeiros e Fronteiras. Relatório estatístico anual, 2010).

${ }^{3}$ PIRES, Rui Pena (coord.). Portugal - Atlas das migrações internacionais; ROCHA-TRINDADE, Maria Beatriz. "História da imigração em Portugal", p. 170-173; VALENTE ROSA, J. Maria; SEABRA, Hugo de; SANTOS, Tiago. Contributos dos "Imigrantes" na Demografia Portuguesa: O papel das populações de nacionalidade estrangeira.

${ }^{4}$ OIM. Medir a Integração: o Caso de Portugal. Indicadores regionais de inserção socioeconómica dos nacionais de países terceiros, p. 28, apud MIRANDA, Joana. Mulheres imigrantes em Portugal. Memórias, dificuldades de integração e projectos de vida.

${ }^{5}$ MIRANDA, op. cit.

${ }^{6}$ TROVÃO, Susana; RAMALHO, Sonia. Repertórios femininos em construção num contexto migratório pós-colonial: Dinâmicas familiares, de género e geração.

7 PIRES, op. cit.

${ }^{8}$ MALHEIROS, Jorge. Imigrantes na Região de Lisboa: Os anos de Mudança. Imigração e Processos de Integração das Comunidades de Origem Indiana. 
a situação das três comunidades mais representativas na atualidade: brasileira, cabo-verdiana e ucraniana. ${ }^{9}$

Com tempos de permanência distintos, os imigrantes oriundos de diversos países apresentam diferentes estratégias de integração na sociedade portuguesa, em que o domínio (ou não) da língua portuguesa é um importante elemento no processo de integração da sociedade portuguesa. A diversidade de origens nacionais dos fluxos migratórios que, entretanto, se fixaram em Portugal colocam novas questões e levantam desafios, em termos de integração sociocultural, uma vez que muitos destes grupos nacionais - como é o caso da imigração proveniente da China - são amplamente diferenciados em termos de língua, cultura, clima e religião.

\section{O Multiculturalismo, multiculturalidade e interculturalidade}

O grande desafio cultural para a Europa é a escolha entre uma sociedade multicultural ou intercultural. Jacques Delors assinalou que, acima de tudo,

trata-se de aprender a viver em conjunto, conhecendo melhor os outros, a sua história, as suas tradições e a sua espiritualidade e, a partir daí, criar um espírito novo que leve à realização de projetos comuns ou à solução inteligente e pacífica dos inevitáveis conflitos, graças justamente a esta compreensão de que as relações de interdependência são cada vez maiores e a uma análise partilhada dos riscos e dos desafios do futuro. ${ }^{10}$

\footnotetext{
${ }^{9}$ MIRANDA, op. cit.; MALHEIROS, Jorge (org.). Imigração Brasileira em Portugal; PADILLA, Beatriz. "Integration of Brazilian Immigrants in Portuguese Society: Problems and Possibilities", 2005; IDEM. "Integration of Brazilian Immigrants in Portuguese Society: Problems and Possibilities", 2004; MACHADO, Fernando Luís. Contrastes e Continuidades. Migração, Etnicidade e Integração dos Guineenses em Portugal; IDEM. "Imigrantes e estrutura social"; GÓIS, Pedro (org.). Comunidade(s) Cabo-verdiana(s): As Múltiplas Faces da Imigração Cabo-verdiana; SERTÓRIO, Elsa; PEREIRA, Felipa Sousa. Mulheres Imigrantes; FRANÇA, Luís de (coord.). A comunidade Cabo Verdiana em Portugal; GOMES, Isabel Brigham (coord.). Estudo de Caracterização da Comunidade Cabo Verdiana Residente em Portugal; BAGANHA, Maria; MARQUES, José Carlos; GÓIS, Pedro (orgs.). Imigração ucraniana em Portugal e no sul da Europa: a emergência de uma ou várias comunidades; DIONÍSIO, Elsa. Políticas Locais e Acção Colectiva dos Imigrantes da Europa de Leste no Concelho de Lisboa; BÄCKSTRÖM, Bárbara. Saúde e Imigrantes. As Representações e as Práticas sobre a Saúde e a Doença na Comunidade Cabo-Verdiana em Lisboa.

${ }^{10}$ Apud STAVENHAGEN, Rodolfo. Multiculturalidade e Conhecimento: Novas Dinâmicas, p. 15.
} 
Atualmente não faz mais sentido falar de uma só cultura e tornase urgente um diálogo em que cada cultura reconheça a outra como diferente de si, e não como inferior ou superior.

Barbosa ${ }^{11}$ assinala três tipos de respostas da sociedade à diversidade cultural, identificados por Hannoun: 1) Assimilacionismo, que "defende o primado de uma das culturas em presença e a incompatibilidade entre as diferentes culturas" ${ }^{\prime 2}$. Fundamenta-se na ideia de que existe uma cultura universal que deve ser assimilada pelas outras. Como consequência cria um contexto favorável à desigualdade de oportunidades. 2) Multiculturalismo, que "consiste na afirmação por parte de cada grupo de que a sua cultura é essencialmente diferente das outras ${ }^{\prime 13}$. Consequentemente, os grupos culturalmente minoritários são forçados a assumir uma espécie de biculturalismo. Numa perspetiva multiculturalista a cada cultura corresponde um espaço, sendo a sociedade uma atomização cultural. 3) O interculturalismo "é sinónimo de reconhecimento do pluralismo cultural, quer dizer, simultaneamente, a afirmação de cada cultura, considerada na sua identidade própria"14. A complementaridade pressupõe um enriquecimento mútuo que leva à construção de uma cultura comum. Significa que qualquer cultura sai enriquecida do contato com as outras. É estabelecida, assim, uma "relação dialética profunda das diversas culturas particulares entre si e destas com uma cultura universal"15.

O verdadeiro desafio consiste em passar do multicultural ao intercultural, isto é, reconhecer e valorizar a diferença. Não basta somente que as diferentes culturas consigam uma convivência no respeito mútuo e na solidariedade, apesar de isso por si só ser positivo, mas devem conseguir uma interação significativa das culturas em presença. Desde esta perspetiva nenhuma cultura é "intrusa" noutra sociedade, "nenhum indivíduo deve ser visto como um "intruso cultural" na Europa. O conhecimento do contributo de todas as civilizações para o pensamento humano, para a racionalidade é o ponto de partida essencial do intercultural"16.

Admitindo a diferenciação cultural das sociedades, devido à entrada de populações migrantes de proveniências diversas, a abordagem

\footnotetext{
${ }^{11}$ BARBOSA, João. "Currículos para a Diversidade Cultural. Do Debate Teórico à Prática".

${ }^{12}$ Ibidem, p. 22.

${ }^{13}$ Ibidem.

${ }^{14}$ Ibidem, p. 23.

${ }^{15}$ Ibidem.

${ }^{16}$ PEROTTI, Antonio. A Apologia do Intercultural, p. 23.
} 
multiculturalista acaba por entender as populações como culturalmente estanques. Cada minoria étnica é vista como socialmente homogênea e com fronteiras bem definidas, sendo sobrevalorizada a diversidade étnica e ignorados outros fatores como a classe social, gênero ou religião, que contribuem igualmente para a construção das identidades e introduzem diferenças de valores e estilos de vida. Ao contrário do que defende o multiculturalismo, esses fatores combinam-se de forma complexa e são acionados pelos imigrantes de acordo com o contexto.

De fato, ao defender incondicionalmente a coexistência de diferentes identidades culturais, o multiculturalismo encerra em si mesmo fatores de discriminação. Por exemplo, a excisão entre as guineenses ${ }^{17} \mathrm{ou}$ os projetos de autonomia de muitas jovens muçulmanas ${ }^{18}$ não poderem ser concretizados por não se coadunarem com a respetiva tradição e cultura. A multiplicidade de experiências e pertenças conduz a uma diversidade de influências na constante construção e reconstrução dos percursos identitários.

Relativamente ao conceito de multiculturalidade, este se aproxima do anterior e confunde-se parcialmente com a interculturalidade. Os estudos em Portugal sobre multiculturalidade remetem para questões da educação e comunicação intercultural fundamentalmente focados em programas e projetos educativos. A multiculturalidade pressupõe a convivência e respeito mútuo entre culturas.

A interculturalidade pode ser vista como um modelo que permite uma mais-valia e com a qual se ganha em crescimento e multiplicação de perspetivas, onde há um enriquecimento cultural e social e laços de partilha entre pessoas e grupos. A língua, por exemplo, é um dos elos fundamentais para que a interculturalidade seja posta em prática e permitindo uma plena integração no seu verdadeiro sentido, na qual os cidadãos exercem direitos e deveres de forma participada e informada.

A interculturalidade surge enquanto um desafio onde é necessário ser capaz de reconhecer e valorizar a diferença. Não basta somente que as diferentes culturas consigam uma convivência no respeito mútuo e na solidariedade, a interculturalidade implica uma interação significativa

\footnotetext{
${ }^{17}$ MARTINGO, Carla. O Corte dos Genitais Femininos em Portugal: O Caso das Guineenses. Estudo Exploratório.

18 ABRANCHES, Maria. Pertenças Fechadas em Espaços Abertos. Estratégias de (re)Construção Identitária de Mulheres Muçulmanas em Portugal; TIESLER, Nina Clara. "Muçulmanos na margem: a nova presença islâmica em Portugal".
} 
das culturas em presença, através do diálogo e do conhecimento mútuo. De acordo com esta perspetiva, cada cultura vale por si própria e juntas enriquecem-se umas às outras, formando uma cultura em comum. Desta feita, a interculturalidade pressupõe o reconhecimento dos contributos de todos, incluindo imigrantes e minorias.

É neste contexto que surge o conceito de interculturalidade, usado para indicar um conjunto de propostas de convivência democrática entre diferentes culturas, procurando a integração entre elas sem anular a sua diversidade, ao contrário, fomentando o potencial criativo e vital resultante das relações entre diferentes agentes e seus respetivos contextos. ${ }^{19}$

O Quadro 1 torna claro que os diferentes modelos de gestão de sociedades culturalmente diversas têm implicações distintas no modo como sujeitos oriundos de diferentes culturas poderão (ou não) conviver e criar uma sociedade culturalmente diversa.

\section{Quadro 1}

\begin{tabular}{|c|c|c|}
\hline & $\begin{array}{c}\text { Manutenção da cultura } \\
\text { de origem }\end{array}$ & $\begin{array}{c}\text { Adoção de elementos de } \\
\text { identidade cultural maioritária }\end{array}$ \\
\hline Assimilacionismo & NÃO & SIM \\
\hline Multiculturalismo & SIM & NÃO \\
\hline Exclusão & NÃO & NÃO \\
\hline Interculturalidade & SIM & SIM \\
\hline
\end{tabular}

Fonte: Malheiros, 2011

\section{Portugal \\ As políticas públicas para a integração dos imigrantes em}

O fato de os imigrantes constituírem 5\% do total da população em Portugal e $10 \%$ da população ativa, conduziu à necessidade de se criarem mecanismos legais que permitissem a regulamentação, monitorização e integração dos imigrantes na sociedade portuguesa.

A lei da Imigração ${ }^{20}$ e a lei da Nacionalidade ${ }^{21}$ constituem instrumentos fundamentais para a regulação da integração dos imigrantes e servem de base para regulamentar este fenômeno em Portugal. Contudo têm sido desenvolvidos outros instrumentos de apoio à integração dos imigrantes que também operam com muita força nestes processos jurídico-legais.

\footnotetext{
${ }^{19}$ FLEURI, Reinaldo Matias. "Intercultura, educação e movimentos sociais no Brasil".

${ }^{20}$ Lei $\mathrm{n}-23 / 2007$, de 4 de Julho.

${ }^{21}$ Lei orgânica nํ2/2006, de 17 de Abril.
} 
Um novo contexto exigiu da sociedade portuguesa o desenvolvimento de uma política de acolhimento e integração de imigrantes mais consistente, coordenada, desde 1996, pelo Alto Comissariado para a Imigração e Minorias Étnicas (ACIME), órgão dependente do Primeiro Ministro e do Ministro da Presidência e, desde 2007, com a designação de ACIDI IP (Alto Comissariado para a Imigração e Diálogo Intercultural Instituto Público).

O ACIDI IP é um instituto público integrado na administração indireta do Estado, dotado de autonomia administrativa. O ACIDI IP, prossegue atribuições da Presidência do Conselho de Ministros, sob superintendência e tutela do Primeiro-Ministro ou de outro membro do Governo integrado na Presidência do Conselho de Ministros. É-lhe atribuída a missão ${ }^{22}$ de promover a integração dos imigrantes e minorias étnicas na sociedade portuguesa, assegurar a participação e a colaboração das associações representativas dos imigrantes, parceiros sociais e instituições de solidariedade social na definição das políticas de integração social e de combate à exclusão, assim como acompanhar a aplicação dos instrumentos legais de prevenção e proibição das discriminações no exercício de direitos por motivos baseados na raça, cor, nacionalidade ou origem étnica. Na estrutura do ACIDI existem dois órgãos essenciais para a integração dos imigrantes: O Centro Nacional de Apoio ao Imigrante (CNAI) e o Observatório da Imigração.

Os CNAI foram criados em 2004 com o intuito de dar resposta a algumas das dificuldades sentidas pelos imigrantes no seu processo de integração em Portugal. O que se pretendeu foi criar um centro que reunisse, num mesmo espaço, diferentes serviços, instituições e gabinetes a que usualmente os imigrantes têm que recorrer. Um dos fatores de inovação dos CNAI prende-se com a utilização de mediadores interculturais, de diferentes origens, dominando diferentes línguas, preparados para prestarem serviços de apoio aos imigrantes, tendo em conta as suas variadas origens. Um aspeto importante prende-se com o fato de estes mediadores, eles próprios, terem vivido experiências migratórias idênticas a quem os procura. Os mediadores possibilitam que o atendimento seja realizado em 12 línguas e dialetos distintos. Caso surja alguma pessoa que fale um idioma que não seja dominado por nenhum dos mediadores, existe a possibilidade de se recorrer ao Serviço de Tradução Telefônica, que cobre cerca de 60 idiomas.

${ }^{22}$ A missão específica do ACIDI encontra-se consagrada no Decreto-Lei no 167/2007 de 3 de Maio. 
Em 2003 foi criada a Rede de Centros Locais de Apoio à Integração de Imigrantes (CLAII). Esta Rede integra cerca de 100 gabinetes distribuídos por todo o país, procurando que seja prestado um atendimento personalizado. Os CLAll são gabinetes de acolhimento, informação e apoio descentralizado, com ligação aos CNAI, visando ajudar a responder a necessidades de várias ordens dos imigrantes, nomeadamente no que toca à regularização da situação migratória, à aquisição da nacionalidade, ao reagrupamento familiar, às questões do trabalho, da segurança social, da saúde e da educação, entre outras que possam eventualmente surgir. Os CLAII procuram igualmente dinamizar atividades na área da interculturalidade a nível municipal.

Com o Observatório da Imigração, o ACIDI pretende aprofundar o conhecimento sobre esta realidade em Portugal, para poder definir, executar e avaliar políticas eficazes de integração para as populações imigrantes. O Observatório tem um sítio na internet ${ }^{23}$ que visa disponibilizar o acervo de informação de forma gratuita e em regime de repositório aberto acessível a todos que queiram conhecer esta problemática e fomentar a recolha de dados ou de informações complementares. O Observatório da Imigração estimula igualmente a investigação em colaboração com instituições científicas e acadêmicas competentes na matéria, procurando, desta forma, fundamentar, orientar e melhorar as políticas públicas com incidência na problemática da imigração. Promove igualmente seminários, colóquios, debates e outras atividades conducentes ao melhor conhecimento dos fenômenos associados a movimentos de população que tem como destino Portugal. Este Observatório pretende intervir essencialmente como um catalisador de atividades e um promotor de redes de cooperação acadêmica, científica e institucional.

A identificação e a implementação de políticas de integração tornaram-se questões centrais da agenda dos estados comunitários. Não existindo um padrão definido de boas práticas para todos os estados, cada estado deverá definir as suas boas práticas. O MIPEX - Migration Integration Policy Index reuniu um conjunto de 140 indicadores sobre aspectos concretos das políticas de integração de imigrantes em 25 estados membros da União Europeia e em três países não pertencentes à União - Canadá, Noruega e Suíça. De acordo com a avaliação de $2006^{24}$,

\footnotetext{
${ }^{23}$ Cf. www.oi.acidi.gov.pt.

${ }^{24}$ Está prevista uma atualização de dois em dois anos.
} 
Portugal ocupa uma posição favorável no ranking relativamente a várias das dimensões de análise consideradas, nomeadamente, nas dimensões de acesso ao mercado de trabalho, reunificação familiar e antidiscriminação, dimensões em que ocupa a segunda posição do ranking.

Em Abril de 2011, apresentaram-se os resultados da 3a edição do estudo Migrant Integration Policy Index - MIPEX II e III25 e discussão das conclusões. Este projeto avalia e compara, desde 2004, as políticas de imigração vigentes em 31 países (os 27 Estados-membros da União Europeia e a Noruega, a Suíça, o Canadá e os Estados Unidos da América), através de 148 indicadores: à semelhança da segunda edição deste estudo, Portugal continua a ser o segundo país com melhores políticas de integração de imigrantes. A encabeçar a lista está a Suécia. Para avaliar o caminho que o imigrante tem que percorrer até a sua plena integração no país de acolhimento, este ranking tem em conta sete áreas dentro das políticas de integração: acesso ao mercado de trabalho; reagrupamento familiar; educação; participação política; residência permanente; acesso à nacionalidade e antidiscriminação. Portugal obtém o primeiro lugar no que concerne ao acesso à nacionalidade e às políticas de reagrupamento familiar.

No contexto português, o Plano para a Integração dos Imigrantes (PII) ${ }^{26}$ constitui um programa político que pretende atingir níveis superiores de integração, quer numa perspetiva setorial, designadamente nas áreas do Trabalho, Habitação, Saúde e Educação, quer numa perspetiva transversal no que toca às questões do racismo e discriminação, igualdade de gênero e cidadania. O PII I definiu um roteiro de compromissos concretos que, na vertente das políticas de integração, veio reforçar o papel do Estado como o principal aliado da integração dos imigrantes.

Desde 2010 está em curso o PII II, o que veio provar o sucesso da implementação do primeiro. O relatório de avaliação da implementação das medidas do PII I concluiu que a taxa de execução foi muito elevada - cerca de $81 \%$-, sendo que em muitos domínios foi mesmo possível ultrapassar as metas propostas.

\footnotetext{
${ }^{25}$ NIESSEN, Jan; HUDLESTON, Thomas; CITRON, Laura et alii. Index de Políticas de Integração de Migrantes; HUDDLESTON, Thomas; NIESSEN, Jan. MIPEX Index III.

${ }^{26}$ Resolução do Conselho de Ministros n.o 63-A/2007, DR 85 SÉRIE I de 2007-05-03. O PII foi elaborado a partir de um trabalho conjunto de todos os ministérios com contributos das organizações da sociedade civil recolhidos durante um período de discussão pública e que resultou num documento que espelha as sensibilidades da sociedade portuguesa.
} 
Este Plano inclui 90 medidas e abrange uma intervenção em 17 áreas, quatro delas novas: diversidade, interculturalidade, idosos imigrantes e imigrantes em situação de desemprego. O novo PII assenta na avaliação do Plano anterior e na identificação das necessidades de intervenção para o período 2010-2013, beneficiando novamente da contribuição de todos os ministérios e da participação da sociedade civil, em especial através das associações de imigrantes ou que trabalham com imigrantes.

Apesar de ser fundamental analisar as políticas imigratórias do país, há que ter em conta que as mesmas devem incluir uma vertente transnacional, procurando uma coordenação efetiva com os países de origem dos imigrantes. Devem desenvolver-se de forma articulada no sentido de garantir oportunidades de trabalho com o mesmo nível de reconhecimento e igualmente remuneradas para homens e mulheres; acesso gratuito à educação para os seus filhos. Apesar de na própria Constituição da República Portuguesa esse direito estar consignado, o acesso à educação pré-escolar continua a ser muito limitado, situação que não é específica dos imigrantes, mas que se aplica a toda a população; acesso à informação pois, apesar dos avanços, muitos imigrantes continuam a não ter acesso à informação que lhes permitiria uma integração mais efetiva sobre os seus direitos e deveres enquanto imigrantes e o reconhecimento de qualificações, entre outros. Apesar de terem sido desenvolvidas algumas medidas a este nível, continuam a ser inúmeros os estrangeiros com qualificações de nível superior que exercem atividades indiferenciadas em Portugal.

\section{As estratégias de integração e a convivência entre imigrantes}

O modo como uma pessoa é acolhida num novo grupo ou sociedade e, particularmente, num novo país onde procura refazer a sua vida, marca a diferença em todo o percurso da sua inserção. Para a integração revelam-se importantes fatores como ter um trabalho, o domínio da língua, a integração dos filhos na escola, os processos de legalização, a existência de rede de apoio, a aquisição de casa própria, a possibilidade de reagrupamento familiar, entre outros. A integração dos imigrantes nas sociedades de acolhimento é um processo complexo e multifacetado. Demetrios Papademetriou ${ }^{27}$ define integração como o processo de interação, ajustamento e adaptação mútua entre imigrantes e a sociedade de acolhimento, pelo qual ao longo do tempo, as comunidades recém-

${ }^{27}$ PAPADEMETRIOU, Demetrios. Policy considerations for Immigrant Integration. 
chegadas e a população dos territórios de chegada formam um todo integrado. Na mesma linha de pensamento, Rinus Pennin $x^{28}$, considera a integração como o processo de aceitação dos imigrantes pela sociedade receptora, como indivíduos e como grupos. Ambos os autores enfatizam a diversidade de atores intervenientes no processo de integração: imigrantes, governos, instituições e comunidades locais. Deste modo, as formas de inserção dos imigrantes nas sociedades receptoras são processos dinâmicos, em permanente mudança, resultantes de influências bastante diversas ao nível da macroestrutura econômica, social, política e institucional, dos países de destino no momento da migração e das especificidades dos contextos locais dos territórios onde se fixam. Daqui resulta que as formas de incorporação dos imigrantes nas sociedades de acolhimento são bastante mais complexas e matizadas do que a simples oposição entre regimes nacionais assimilacionistas e multiculturalistas poderia fazer crer. Os imigrantes são co-habitantes ativos de um lugar e co-produtores de uma cultura local. Por isso, as trajetórias de integração são processos de adaptação criativa às condições de vida locais e à (re)construção coletiva e cooperativa dos territórios onde vivem, envolvendo um processo de aprendizagem mútua, feito de cooperação e conflito, diálogo e troca de saberes, experiências e práticas culturais entre indivíduos, grupos sociais ou comunidades étnicas que partilham o mesmo espaço geográfico. A gestão da diversidade econômica, social e cultural, potenciadora de conflitos, mas também de inovação social, constitui um dos desafios mais importantes que se colocam à sustentabilidade das cidades do futuro. ${ }^{29}$

Em momentos de crise econômica, os imigrantes tendem a ser mais afetados do que os nacionais, o que se prende com o fato de possuírem posições menos qualificantes e menos remuneradas, apresentando um maior risco de desemprego. ${ }^{30}$ Desta feita, os imigrantes, sobretudo os indocumentados e as minorias étnicas pobres, são particularmente afetados, porque são menos qualificados, têm vínculos de trabalho mais precários e, nestes períodos de crise, tendem a aumentar as atitudes discriminatórias e hostis por parte de alguns setores da população autóctone, que os encaram como potenciais concorrentes no mercado de emprego, ou dos apoios concedidos pelas Instituições de Segurança Social. Por outro lado, as épocas de expansão econômica podem constituir ambientes favoráveis

\footnotetext{
${ }^{28}$ PENNINX, Rinus. Integration: the Role of Communities, Institutions, and the State.

${ }^{29}$ FONSECA, Maria Lucinda; CALDEIRA, Maria José; ESTEVES, Alina. "New forms of migration into the European South: challenges for citizenship and governance: the Portuguese case".

${ }^{30}$ OCDE. International Migration Outlook: SOPEMI 2009.
} 
ao desenvolvimento de iniciativas empresariais que, com o tempo, podem dar origem a um importante empreendorismo de base étnica, criando oportunidades de emprego para trabalhadores co-étnicos, entre outros.

No caso português, apesar de uma enorme diversidade de origens nacionais, salienta-se o pouco contato entre sujeitos de diferentes origens, portadores de visões do mundo distintas. Ou seja, diferentes grupos nacionais partilham um mesmo espaço sem que haja convivência propriamente dita.

A quase inexistência de estudos sobre a convivência entre membros de culturas diferentes em Portugal é reveladora de uma realidade que não se observa. Os estudos sobre as comunidades imigrantes nas duas últimas décadas, têm sobretudo focado grupos de diversas nacionalidades, mas de forma isolada e quando falam de múltiplas origens, fazem-no numa perspetiva comparativa, lado a lado e nunca entrecruzada, demonstrando sobretudo as diferenças em vez de encontrar as convivências e os pontos de contato.

A integração não é a única dimensão que importa aferir e acompanhar. É sobretudo importante perceber como os próprios migrantes autopercepcionam a sua trajetória, se estão satisfeitos e realizados com a decisão de terem embarcado neste projeto migratório individual e se voltariam a tomar a mesma decisão. No fundo ao estarem integrados, diluem-se na sociedade de acolhimento aproximando os discursos, comportamentos e práticas aos da população autóctone, transformando essa própria sociedade que, ao incorporar a cultura do Outro, conduz ao enriquecimento da cultura e da sociedade. É usual ouvir-se falar dos africanos, dos brasileiros e dos imigrantes de leste como categorias homogêneas sem que se tenha em conta que imigrantes têm muitas e diferentes origens e não têm necessariamente que morar, conviver, nem partilhar os mesmos espaços públicos.

Parece-nos igualmente importante aferir quais as estratégias de integração dos imigrantes. As estratégias de integração podem ser definidas como sendo as formas através das quais os imigrantes lidam, na sua ação individual, familiar e de grupo, com as condições encontradas nas sociedades receptoras. ${ }^{31}$ Mas, estas estratégias são elas próprias dinâmicas, pois quando as condições se alteram, as estratégias alteram-se também.

${ }^{31}$ MACHADO, Fernando Luís; ROLDÃO, Cristina; SILVA, Alexandre. Vidas Plurais: estratégias de integraçãode imigrantes africanos em Portugal, p. 29. 
Apesar de muitos dos estudos disponíveis sugerirem uma homogeneidade entre imigrantes, na realidade, em Portugal assistese a uma reconfiguração cultural, de novas identidades baseadas em reportórios culturais híbridos e heterogêneos, experiências de vida complexas e uma pluralidade de Outros generalizados.

As situações de pluriculturalidade, podem muitas vezes ser objeto de interpretações ambíguas, que estão quase sempre na origem da rejeição do próprio conceito de sociedade pluricultural. Pois, "não podemos conceber a sociedade pluricultural e falar dela como se se tratasse de um mosaico onde os grupos e as comunidades da língua, de cultura e de etnia ou de religião diferentes fossem simplesmente justapostos. Uma tal concepção é tributária de uma visão estática de cultura; ela desconhece a interação entre indivíduos, grupos e comunidades, assim como as condições que explicam o sucesso ou insucesso da interação" ${ }^{32}$. Tendo em consideração esta definição, uma sociedade pluricultural supõe uma longa série de negociações entre as instituições e os grupos minoritários, uma vez que a coexistência, num mesmo espaço geográfico de grupos étnicos e culturalmente diversificados nem sempre é pacífica. Já que geram tensões que se traduzem numa imposição a toda a sociedade dos modelos culturais dos grupos dominantes, na dificuldade da promoção das diferenças, na depreciação das culturas minoritárias ou menos poderosas, na pressão para que essas culturas assumam modelos com os quais e segundo os quais têm de sobreviver, no encerramento de cada cultura sobre si, o que obsta às trocas entre os diferentes grupos culturais e consequentemente ao enriquecimento mútuo. ${ }^{33}$

Desde aqui surgem novos problemas e desafios, já que a convivência pacífica de diferentes comunidades deverá encontrar uma base mais sólida que a imposição de uma cultura sobre a outra. O convívio entre culturas, num contexto de globalização econômica, social e cultural, torna-se um desafio e um problema, onde, por um lado, se assiste a uma convergência cultural, mas por outro lado, a uma afirmação cada vez maior das próprias culturas. Com o aumento dos fluxos migratórios culturalmente distintos, os confrontos entre culturas, fruto do aumento da heterogeneidade das sociedades, irão certamente crescer nos países da Europa do sul.

\footnotetext{
${ }^{32}$ PEROTTI, op. cit., p. 43.

${ }^{33}$ BARBOSA, op. cit.
} 


\section{Notas Finais}

Para onde quer que hoje olhemos, resulta evidente que a circulação de pessoas, bens e ideias atingiu uma tal dimensão que se tornou um dos fenômenos mais marcantes da contemporaneidade. A configuração estrutural das sociedades receptoras e o que estas sociedades impõem como constrangimentos e oferecem como oportunidades são fundamentais nas estratégias de integração dos imigrantes. ${ }^{34}$

A ação individual dos imigrantes é um importante fator para a integração e convivência entre culturas. No plano macro, para que a convivência entre culturas seja uma realidade é fundamental a existência de um quadro legislativo favorável. Mas o plano micro, i.e., o das vivências quotidianas dos imigrantes nos diferentes domínios da sua vida, é crucial para que haja uma efetiva integração e convivência entre diferentes grupos.

Apesar de ser hoje mais ou menos consensual que a diversidade contribui para o enriquecimento de uma sociedade, frequentemente esta diversidade é encarada unicamente como algo meramente folclórico. No entanto, a abertura ao Outro implica necessariamente a vontade e criação de condições para uma transformação recíproca.

Considerando que atualmente, em Portugal, 5\% da população é estrangeira, a convivência entre culturas afigura-se como um desafio basilar, indo para além do mero conhecimento da cultura do Outro. A interculturalidade implica uma atitude transformativa, em que sujeitos portadores de diferentes culturas e visões do mundo distintas se transformam mutuamente e se (re)configuram ininterruptamente na relação que estabelecem com o(s) Outro(s).

\section{Bibliografia}

ABRANCHES, Maria. Pertenças Fechadas em Espaços Abertos. Estratégias de (re) Construção Identitária de Mulheres Muçulmanas em Portugal. ACIDI, OI, colecção teses, n. 13, Lisboa, 2007.

ACIDI/Presidência do Conselho de Ministros. Plano Para a Integração dos Imigrantes. Resolução do Conselho de Ministros n. 63-A/2007, 3 de Maio, Lisboa, 2007. . Plano Para a Integração dos Imigrantes. Relatório Anual de Execução, Maio 2007-Maio 2008, Resolução do Conselho de Ministros n.. 63-A/2007, de 3 de Maio, Julho, Lisboa, 2008.

${ }^{34}$ MACHADO et alii, op. cit. 
BÄCKSTRÖM, Bárbara. Saúde e Imigrantes. As Representações e as Práticas sobre a Saúde e a Doença na Comunidade Cabo-Verdiana em Lisboa. Colecção Teses, 24. Lisboa: ACIDI, 2009.

BAGANHA, Maria I.; MARQUES, José Carlos; GÓIS, Pedro (org.). Imigração ucraniana em Portugal e no sul da Europa: a emergência de uma ou várias comunidades. Lisboa: ACIDI, Comunidades, 3, 2010.

BARBOSA, João. "Currículos para a Diversidade Cultural. Do Debate Teórico à Prática", in Revista Inovação, n. 9, 1996, p. 21-34.

COHEN, Ronald. "Ethnicity: Problem and Focus in Anthropology", in Annual Review of Anthropology, v. 7, 1978, p. 379-403.

DIONÍSIO, Elsa. Políticas Locais e Acção Colectiva dos Imigrantes da Europa de Leste no Concelho de Lisboa. Colecção Teses, 27, Lisboa: ACIDI, 2009.

FLEURI, Reinaldo Matias. "Intercultura, educação e movimentos sociais no Brasil", in V Colóquio Internacional Paulo Freire - 2005. Disponível em: www.paulofreire. org.br/Textos/fleuri_2005_recife_resumo_e_texto_completo.pdf.

FONSECA, Maria L.; CALDEIRA, Maria José.; ESTEVES, Alina. "New forms of migration into the European South: challenges for citizenship and governance: the Portuguese case", in International Journal of Population Geography, v. 8, n. 2, 2002, p. 135-152.

FRANÇA, Luís de (coord.). A comunidade Cabo Verdiana em Portugal. Lisboa: Instituto de Estudos para o Desenvolvimento, caderno 23, 1992.

GÓıS, Pedro (org.). Comunidade(s) Cabo-verdiana(s): As Múltiplas Faces da Imigração Cabo-verdiana. Comunidades, 2. Lisboa: ACIDI, 2008.

GOMES, Isabel B.(coord.). Estudo de Caracterização da Comunidade Cabo Verdiana Residente em Portugal. Lisboa: Embaixada de Cabo Verde em Portugal, 1999.

HUDDLESTON, Thomas; NIESSEN, Jan. MIPEX Index III. Lisboa: British Council e Fundação Calouste Gulbenkian, 2011.

LAGES, Mário; POLICARPO, Verónica. Atitudes e valores perante a imigração. Lisboa: Observatório da Emigração, ACIME, 2003.

MACHADO, Fernando Luís. Contrastes e Continuidades. Migração, Etnicidade e Integração dos Guineenses em Portugal. Oeiras: Celta Editora, 2002.

. "Imigrantes e estrutura social", in Sociologia, Problemas e Práticas, v. 29, 1999, p. 51-76.

MACHADO, Fernando L.; ROLDÃO, Cristina; SILVA, Alexandre. Vidas Plurais: estratégias de integraçãode imigrantes africanos em Portugal. Lisboa: Fundação Aga Khan e Tinta-da-china, 2011.

MALHEIROS, Jorge M. Promoção da interculturalidade e da integração de proximidade: manual para técnicos. Lisboa: ACIDI, 2011.

(org.). Imigração Brasileira em Portugal. Lisboa: ACIME, Colecção Comunidades, 1, 2007. 
. Imigrantes na Região de Lisboa: Os anos de Mudança. Imigração e Processos de Integração das Comunidades de Origem Indiana. Lisboa: Colibri, 1996.

MARTINGO, Carla. O Corte dos Genitais Femininos em Portugal: O Caso das Guineenses. Estudo Exploratório. Lisboa: ACIDI, 2009.

MIRANDA, Joana. Mulheres imigrantes em Portugal. Memórias, dificuldades de integração e projectos de vida. Lisboa: Observatório da Imigração, 2009.

NETO Félix. Psicologia Intercultural. Lisboa: Universidade Aberta, 2002.

NIESSEN, Jan et alii. Index de Políticas de Integração de Migrantes. Lisboa: British Council e Fundação Calouste Gulbenkian, 2007.

OCDE. International Migration Outlook: SOPEMI 2009. OCDE, 2009.

OLIVEIRA, Ana; GALEGO, Carla Marques. A Mediação Sócio-Cultural: Um Puzzle em Construção. Observatório da Imigração:14. Lisboa: Acime, 2005.

PADILLA, Beatriz. "Integration of Brazilian Immigrants in Portuguese Society: Problems and Possibilities", in SOCIUS Working Papers, n. 1, 2005, p. 1-18.

. "Integration of Brazilian Immigrants in Portuguese Society: Problems and Possibilities", in 9th International Metropolis Conference "Co-operative Migration Management", September 27 - October 1, Geneva, 2004.

. "O empreendedorismo na perspectiva de género: uma primeira aproximação ao caso das brasileiras em Portugal", Revista Migrações, n. 3, Lisboa: ACIDI, p. 191-215, 2008.

PAPADEMETRIOU, Demetrios. Policy considerations for Immigrant Integration. Migration Information Source, Migration Policy Institute, 2003.

PENNINX, Rinus. Integration: the Role of Communities, Institutions, and the State. Migration Information Source, Migration Policy Institute, 2003.

PEROTTI, Antonio. A Apologia do Intercultural. Lisboa: Secretariado Entreculturas, 1997.

PIRES Rui Pena (Coord.). Portugal - Atlas das migrações internacionais. Lisboa: Fundação Calouste Gulbenkian, Comissão Nacional para as Comemorações do Centenário da República e Edições Tinta-da-China, 2010.

PNUD. Relatório de Desenvolvimento Humano 2009 - Ultrapassar Barreiras: Mobilidade e Desenvolvimento Humanos, 2009.

ROCHA-TRINDADE, Maria Beatriz. "História da imigração em Portugal", in Janus 2001, Anuário de Relações Exteriores, 2001, p. 170-173.

SEF - SERVIÇO DE ESTRANGEIROS E FRONTEIRAS. Relatório Estatístico anual 2009. Oeiras: SEF, 2010.

. Relatório Estatístico anual 2010. Oeiras: SEF, 2011.

SERTÓRIO, Elsa; PEREIRA, Felipa S. Mulheres Imigrantes. Lisboa: Ela por Ela, 2004.

STAVENHAGEN, Rodolfo. Multiculturalidade e Conhecimento: Novas Dinâmicas. Conferência de Abertura do I Encontro da APEDI-Associação de Professores para a Educação Intercultural, 1997. 
TIESLER, Nina Clara. "Muçulmanos na margem: a nova presença islâmica em Portugal", in Sociologia, n. 34, p. 117-144, 2000.

TROVÃO, Susana; RAMALHO, Sonia. Repertórios femininos em construção num contexto migratório pós-colonial: Dinâmicas familiares, de género e geração. Observatório da Imigração, Estudo 42, v. 1, ACIDI, 2010.

VAlENTE ROSA, J. Maria; SEABRA, Hugo de; SANTOS, Tiago. Contributos dos "Imigrantes" na Demografia Portuguesa: o papel das populações de nacionalidade estrangeira. Observatório da Imigração, Estudo 4, ACIME, 2004.

\section{Abstract}

\section{The migration issue and coexistence strategies of different cultures in Portugal}

This article presents a theoretical reflection on the coexistence of different cultures in Portugal. From a brief characterization of immigration in Portugal, at a first moment, an attempt was made to define and distinguish different theoretical models on integration in order to, at a second moment, concretely analyze public policies on the integration of immigrants in the Portuguese society. Finally, based on the fact that studies focus on comparisons between cultures rather than on the coexistence between them, an attempt was made to reflect on the subjacent reasons for the almost total absence of researches with focus on the coexistence of cultures.

Keywords: Immigration in Portugal; Multiculturalism; Interculturalism; Public Policies on Integration.

Recebido para publicação em: 28/02/2012.

Aceito para publicação em: 17/04/2012 Received for publication on February, 28 ${ }^{\text {th }}, 2012$. Accepted for publication in April,17 $7^{\text {th }}, 2012$. 